\title{
Emotional and Aesthetic Attachment to Digital Artefacts
}

\author{
Phil Turner and Susan Turner \\ School of Computing, Edinburgh Napier University \\ Edinburgh, EH10 5DT \\ p.turner@napier.ac.uk, s.turner@napier.ac.uk
}

\begin{abstract}
We report a pair of repertory grid studies that explore the attachment people have for digital and nondigital artefacts.

In the first study we found no clear distinctions between emotional attachment to digital and nondigital artefacts: people are attached to their mobile phones in much the same way as to a childhood teddy bear. There was also evidence that attachment and the physical availability or proximity of the artefact were associated.

In the second study we examined the aesthetics of attachment to digital and non-digital artefacts. Again the proximity or availability of the artefacts appeared to be important. Items that were carried about or worn, such as wristwatches and laptops, were closely associated while TVs and games consoles were not.

In all, there does not appear to be any qualitative differences between the attachment people have for digital and non-digital artefacts. Nor do aesthetics appear to play a part in this attachment. However the physical proximity of these artefacts is strongly associated with our (inward) feelings of attachment to them, while we can also recognise the importance of this relationship to how we (outwardly) present ourselves to the world and others.
\end{abstract}

\section{Keywords}

Qualitative study, attachment, aesthetics, repertory grids 


\section{Introduction}

In an everyday sense, attachment is easily understood. It means caring about, being fond of and being miserable if the object of our affect is absent. Indeed Kagan et al., (1978) write that an attachment is, "an intense emotional relationship that is specific to two people, that endures over time, and in which prolonged separation from the partner is accompanied by stress and sorrow". This is the relationship between mother and child. Psychological studies of attachment have been quite varied and include studies of gosling to ethologist (Lorenz, 1935); infant to care-giver (Bowlby, 1969 among very many others); and the effects of such things as institutional child raising and divorce. However there is no denying that attachment also extends to the non-living, to the material, such as man to sports car or teenager to mobile phone. Schultz et al. (1989) have reported that when they asked people about their feelings about those possessions for which they felt attachment, love was the second most frequently cited (of the 83 emotions ( $\mathrm{sic}$ ) elicited). That our relationship with technology in general goes beyond mere functionality is also reflected in Verbeek's distinction regarding our attachment to the thing itself and to what the thing provides (Verbeek, 2005). Though, by its very nature, emotional attachment to artefacts is to some extent capricious it is reasonable to assume that it is based on a repeated exposure or familiarity. This familiarity is a deep knowledge of, or acquaintance with the artefact. Earlier work on familiarity with digital artefacts (Turner, 2005; Turner and Sobolewska, 2009) has shown that familiarity itself encompasses the ideas of engagement and "know-how". This conjunction of engagement (with the thing in itself) and "know-how" (making use of what the thing provides) is, of course, a re-statement of Verbeek's position.

Kleine and Baker (2004) in their excellent review paper are able to refine this further by recognising different forms of attachment, for example, place attachment ("Paris in the Spring"); brand attachment (e.g. Apple ${ }^{\mathrm{TM}}$ ) and experience attachment (e.g. sky diving). They go on to offer the following definition of material attachment as, "material attachment is a multi-faceted property of the relationship between an individual or group of individuals and a specific material object that has been psychologically appropriated, de-commodified, and singularized through person-object interaction".

The themes of appropriation, de-commodification and singularization are of particular interest here. While these are in no sense orthogonal they can be meaningfully discussed separately while recognising their many overlaps.

\subsection{Appropriation}

The appropriation of digital artefacts in this context means to make it our own, although this does not necessarily require or imply ownership. We happily talk about "my phone" (though it may be on a contract) and we also vehemently distinguish between a work-issued personal computer which we are 
happy for anyone to use and our (work-issued) laptop which is "ours". Appropriation as "making technology our own" can vary from something as trivial such as customising the appearance of the desktop of a computer or the use of mobile phone "skins" through to full blown personalisation which some researchers have called "ensoulment" (e.g. Odom et al., 2009) and here is an overlap with singularization (please section 1.3 below). Personalisation is the process by which an artefact is endowed with greater significance by and for its user. Wells (2000) defines it as "the deliberate decoration or modification of the environment" and associates it with "well-being" and as such it is both evidence of emotional attachment and a consequence of that attachment. Blom and Monk (2003) have shown that personalising the appearance of an artefact has cognitive, social and emotional dimensions. They describe the cognitive aspects of personalisation as improving, for example, ease of use; the social dimensions of personalisation being concerned with reflecting personal and group identity; while the largest category are the emotional effects on the user which might include feelings of familiarity, ownership, control, fun, attachment, release from boredom and other positive attachments. In all personalisation can offer multi-faceted evidence of attachment.

\subsection{Commodities and things}

Borgmann (1984) distinguishes between commodities and things: a commodity is a context-free entity isolated from traditions and customs. A thing, in contrast, is capable of engaging and connecting with us. So, for example, a hamburger bought from a chain is an example of a commodity, whereas a home cooked dinner is a thing. Hamburgers are seen to be uniform, safe, reliable and quantifiable (though may be seen to be contributing to the homogenization of society); while a home-cooked dinner relies on the skill of the cook, the availability of ingredients, time, effort and is an experience not easily susceptible to quantification. One is packaged and delivered (often in an opaque wrapper) while the other is open to inspection, modification and even participation. As for digital artefacts we now buy and use mobile phones, laptops, MP3 players and so forth (often from supermarkets together with the weekly groceries) which are known to be safe, reliable and usable without necessarily having the remotest of ideas of how they work. Yet less than 20 years ago it was not only commonplace to tinker with one's personal computer but often absolutely necessary. Many of us will remember manually editing the startup and configuration files to resolve conflicts in, for example, loading devices into memory. Information technology, then, was a thing requiring familiarity with its operation. In contrast, today there is an increasing dichotomy between the user interface and the "black box" which lies beneath. Microsoft discourage us from tinkering with operating system files while other manufacturers have been described as having adopted a "walled-garden" approach.

Observations such as these have given rise to Borgmann's concept of the device paradigm which is an account of technology use in which people treat it purely instrumentally. Technology, for example, makes the procurement of goods "instantaneous, ubiquitous, safe, and easy" (Borgmann, 1984: 41) - 
witness the convenience of online shopping. These pressures and opportunities will tend to make us treat technology as a commodity rather than a thing of value, personal meaning and attachment - again this discussion is shading into singularization.

\subsection{Singularization}

Kleine and Baker (2004) describe singularity as being associated with an unwillingness to sell the possession for market value; as being irreplaceable and non-substitutable. Singularization is also associated with self-extension (i.e. artefacts standing for or presenting oneself to the world). This is clearly closely conceptually related to the notion of "special objects" which Csikszentmihalyi and Halton-Roch (1981) investigated in their 1977 study of 82 North American households. Among the qualities of objects nominated as special were the embodiment of memories or associations with others, uniqueness, style and enjoyment, and the expression of some aspect of the self. Rather more recently, researchers in the field of Sustainable Interaction Design (SID) have introduced the concept of the ensoulment of objects, which is also closely related to attachment. Here, ensoulment signifies the properties of "well-loved" designs that embody meaning and reflect their owner's identities and values (Nelson and Stolterman, 2003; Blevis, 2007; Akah and Bardzell, 2010). Ensoulment or attachment may be viewed, inter alia, as a consequence of personalisation or enchantment. (McCarthy and his colleagues, 2005, offer a discussion of enchantment as follows: "An object or interactive system that is likely to evoke enchantment should offer the potential for the unexpected, give the chance of new discoveries, and provide a range of possibilities.") Ensoulment is likely to encourage the preservation of an object even though it is no longer up-to-date or even useful and may lead to an artefact acquiring "heirloom status" - affording being passed on to others (Blevis, 2007). Promoting ensoulment is thus a priority for designers concerned with the sustainability of the designed artefact; accordingly a number of researchers in the SID community have investigated the nature of the individual's emotional relationship or attachment to personal possessions.

\subsection{Evidence for Attachment to Technology}

Against this background it is interesting to note the conclusions of Odom and Pierce (2009) who report interview-based work probing people's perceptions of digital and non-digital domestic objects. The dimensions explored included attachment, perceptions of new versus old, frequency of use, emotional versus functional value, physical involvement through use, signs of use over time, relative ability to personalize, and perceived durability. Overall, it was concluded that "participants rarely expressed strong attachment to digital artefacts and perceived that digital artefacts rarely improve with age. In many cases, participants did express strong attachment to non-digital products, which oftentimes were perceived to improve with age" (Odom and Pierce, p. 3795). In related work, again involving interviews about personal possessions which focussed in patterns of acquisition, attachment 
and retention Odom et al., (2009) found, "a contrast between the ensoulment of things non-digital and the un-ensoulment of things digital" (p. 1056).

In all, the evidence for attachment to digital artefacts remains equivocal. There is clear evidence for the personalisation of technology, which implies attachment. Yet Borgmann sees a shift from meaningful, socially inscribed things to mass produced, characterless commodities as witnessed by our instrumental use of technology. Finally, the evidence of the ensoulment of traditional technologies stands in contrast to the "un-ensoulment of things digital". From here we now consider how we might study attachment.

\section{Studying Attachment}

The approach we adopted is explicitly qualitative ${ }^{1}$. Our interest is in determining the dimensions of attachment and how these vary across digital and non-digital artefacts and is consistent with much of the work in this area (e.g. Schultz et al., 1989; Kleine, and Baker, 2004; McCarthy et al., 2005; Odom et al., 2009; Odom and Pierce, 2009; Meschtscherjakov, 2009; Akah and Bardzell, 2010; Fallman and Waterworth, 2010 among many others).

As we have already noted, attachment is something which develops over time and as such requires a technique which will capture well established perceptions or constructs. It is for this reason that we have selected the use of repertory grids to investigate attachment. Repertory grids have their origins in Kelly's personal construct theory (Kelly, 1955). Kelly, a clinical psychologist, held that individuals act as personal scientists in that they classify, and interact with, people known to them according to a repertory of dimensions (or constructs) which are personally important to that individual and are grounded in their experience of interacting with others. While Kelly's interest was confined to that domain, the technique has since been adopted and adapted to explore an individual's experience, perceptions or knowledge of any set of objects of interest to the researcher.

However before we consider how the technique is applied, we should say a little for about the nature of constructs. Kelly tells us that an individual's personal constructs might be referred to in other psychological approaches as "personality”, “attitudes”, "habits” or "concepts”. Kelly (1969) writes that, "A construct is like a reference axis, a basic dimension of appraisal, often un-verbalised, frequently un-symbolised, and occasionally un-signified in any manner except by the elemental

\footnotetext{
${ }^{1}$ We are, of course, conscious of the debate within the Human-Computer Interaction (HCI) / user experience (UX) communities concerning the use of quantitative and qualitative methods and measures. Some working within $\mathrm{HCI}$ / UX refute measurement arguing that human experiences and feelings cannot be reduced to mere numbers (cf. Davis, 2003). This argument reflects the long standing dispute between the cognitivist and phenomenological approaches (Winograd and Flores, 1987; Dourish, 2001).

However as our interest is primarily exploratory (rather than formal hypothesis testing) we feel it is enough to recognise the debate but not to participate in it.
} 
processes it governs. Behaviourally it can be regarded as an open channel of movement, and the system of constructs provides each man with his open personal network of action pathways ...”. So the use of repertory grids offers a means of understanding an individual's orientation and behavioural readiness towards a particular theme, domain or, in this instance, technology.

Most current practice in the application of repertory grids derives from the procedure originally operationalised by Fransella and Bannister (1977). In brief, the first step in the interview-based process is to have people identify a number of elements (objects or people) in the domain of interest. Next, participants are guided by the interviewer in repeatedly comparing triads of these elements chosen at random. For each triad, the participant is asked "In what way or ways do any two of these elements resemble each other and which is different?" A typical answer may be something like "these two are personal and this one is more general", creating the bipolar construct of "personalised generic". The completed comparison process draws out a set of bipolar constructs which are salient for the individual in this domain. For example, in the case of mobile devices, the final set of ten constructs elicited from a group of participants included social-individual, sender-receiver, and new-conventional (Fallman and Waterworth, 2010).

Elements are then rated on the constructs, usually on a 5- or 7- point scale and their relationship to each other and the constructs can be plotted graphically and analysed. Other methods of deriving elements and constructs are possible but that just described is the most usual. In further extensions and adaptations of the original process, either elements, constructs or occasionally, both are supplied by the researcher and outputs are commonly aggregated in some way to explore shared perceptions. A helpful overview of repertory grids, some of their more recent applications and a detailed example of their use may be found in Edwards et al. (2009), who review the role of the technique in software engineering research.

While the initial uses of repertory grids were in the qualitative exploration of such phenomena as attitudes and neuroses, they have also been used in knowledge elicitation (e.g. Shaw and Gaines, 1987, 1992); to some extent in information system and HCI design (e.g. Dillon and McKnight 1990; McCarthy and O'Connor 1998) and in understanding job design (e.g. Hassard, 1987; Turner, 2000). Representative instances of more recent studies include the work in software engineering described by Edwards and her colleagues; Brinkman and Love (2006), who used repertory grids to generate constructs which formed the basis for a questionnaire for the evaluation of mobile phones and a multimedia player and McWhinnie et al., (2009) have reported the use of the technique in understanding the practice of creative practitioners. Finally, Fallman and Waterworth (2010) is perhaps the most closely related investigation to the work we report here. In their study of the user experience of mobile information technology, the researchers supplied the repertory grid elements of seven different mobile devices. A total of 180 constructs were elicited from 18 participants using the 
method of triadic comparisons, the constructs being subsequently aggregated by means of cluster analysis and semantic grouping to form a final set of ten dimensions. The authors then compiled a composite grid, supporting an account of the shared experience of the devices and the relationship of each device to the others - an approach we have adopted here.

\section{Two Empirical Studies}

\subsection{Study I}

We begin by framing the following initial research question, namely: "What are the differences in emotional attachment between digital and non-digital artefacts?".

\subsection{Method}

As we wanted to explore the experiences and emotional attachment of a large sample of people we created a standard set of constructs. We decided on supplied constructs because we expected the individual artefacts to vary more than how people were attached to them. This approach allows ease of comparison (Tan and Hunter, 2002) and has been used to some effect by Fransella et al. (2004).

\subsubsection{Eliciting constructs (establishing common ground)}

In order to agree a set of constructs we conducted a pilot study. The method adopted, as described by Fransella and Bannister (1977) was as follows for each of eight participants. Each person was asked to identify eight artefacts (elements) to which they felt some attachment. We asked for four of them to be digital and four non-digital. Each elicited element was then written on a separate piece of card. Then using the triad approach, we elicited at least eight characteristics from each participant by which the elements differed. The most common constructs were selected and trialled for operational usability by presenting the 8 elements to the participants who then ranked the elements against the constructs on a five-point scale. Thus if an artefact was rated as "personalised" it might attract a weighting of 1, while a less important element would be rated 4 or 5 .

$$
\begin{aligned}
\text { aesthetically pleasing } & \text { unremarkable } \\
\text { received as a gift } & \text { bought this myself } \\
\text { long term } & \text { short term } \\
\text { reminds me of others } & \text { no association with other people } \\
\text { personalised } & \text { generic } \\
\text { exciting } & \text { everyday } \\
\text { part of who I am } & \text { not really part of me } \\
\text { irreplaceable } & \text { easily replaced }
\end{aligned}
$$

Table 1: the most frequently named constructs

Perhaps not surprisingly, these constructs echo the classes of meaning attributed to 'special objects' in the study reported by Csikszentmihalyi and Halton-Roch (1981). 


\subsubsection{Eliciting elements and applying the constructs}

The participants in this phase comprised fifty-five interviewees, a mixture of men and women in broadly equal proportions. Their ages ranged widely (between 20 and 70), but most were in their twenties. All were unpaid volunteers. Each interviewee was asked to name four digital and four nondigital personal possessions and then to rate each of these elements against the supplied set of constructs, using a scale of 1 to 5 .

\subsection{Individual patterns of attachment}

The data obtained were analysed using the Rep IV analysis package. Rep IV, developed and supplied by the Centre for Person-Computer studies at the University of Calgary, uses cluster and factor analysis to produce graphical representations of data obtained from individuals. (Rep IV manual, n.d.). In this paper, we discuss our results as displayed in the PrinGrid and Focus graph displays. These representations enable groups of elements and constructs to be identified qualitatively through visual inspection (in the PrinGrid) and quantitatively through consideration of the association strengths calculated by the software (in the Focus graph). The PrinGrid displays the results of a principal component analysis. The elements are plotted as labelled points in participants' conceptual space defined by the constructs as lines centred on the means of the element ratings. Elements are placed closest to the constructs on which they are rated most highly. Physical closeness of elements - in this case the digital and non-digital artefacts - reflects perceived similarity. In the same way, constructs which are closely aligned have a degree of equivalence for the participant. An illustrative selection of the grids is now discussed.

Figure 1 has been generated from the data obtained from participant $\mathrm{B}$. This time, we can observe from this figure that the digital and non-digital elements are evenly distributed across experiential space. In this case the constructs of "aesthetically pleasing and "irreplaceable" are associated, as are "part of who I am" and "personalised". 


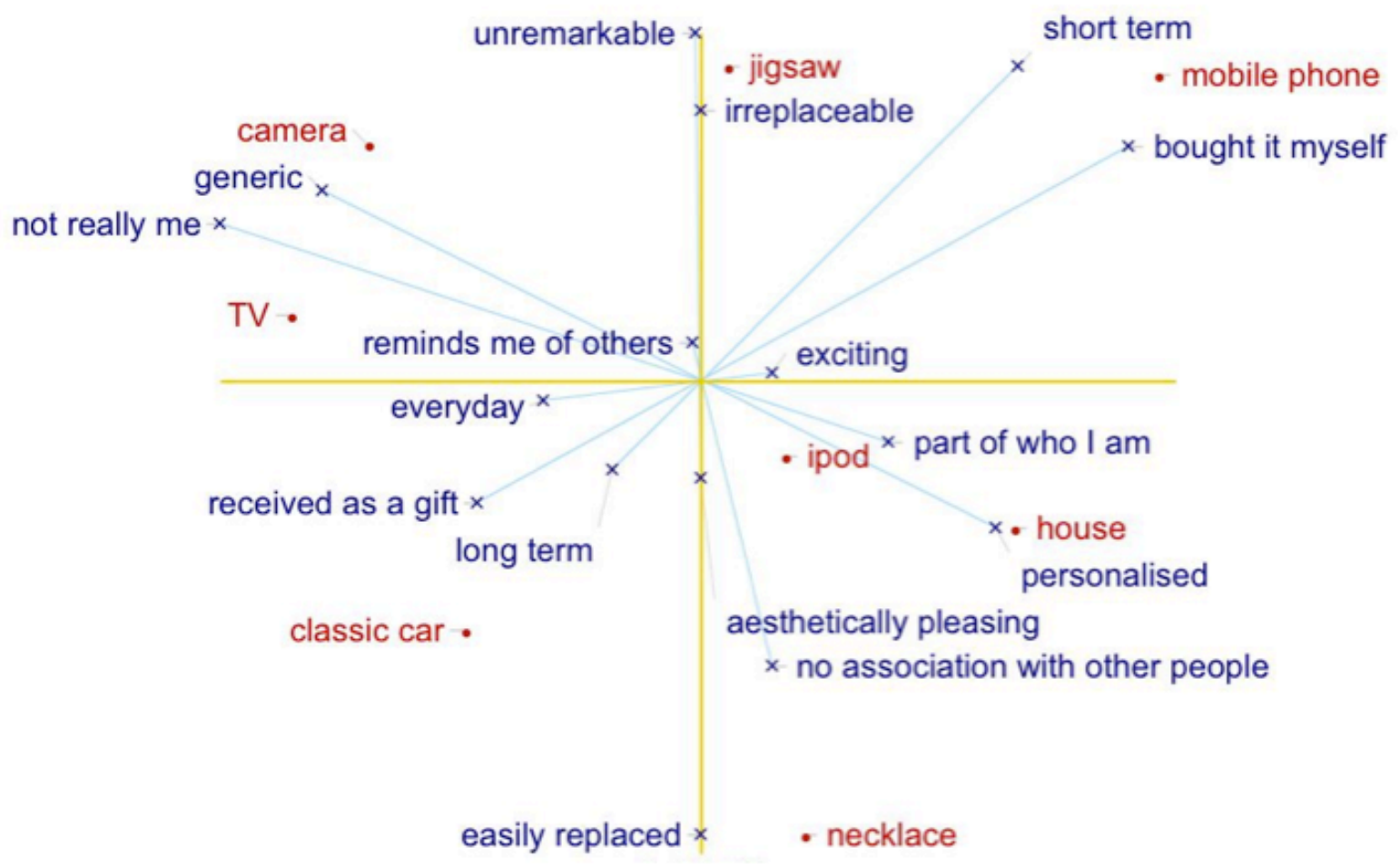

Figure 1:Pringrid for participant B

Figure 2 shows a detail from the Pringrid graph for participant A. Of particular interest is the cluster of jewellery box, necklace and iPod in the bottom-left quadrant, related to the "reminds me of others", "irreplaceable", "long term", aesthetically pleasing" and "received as a gift" poles. This clustering indicates that this participant is attached to these three items in a similar way.

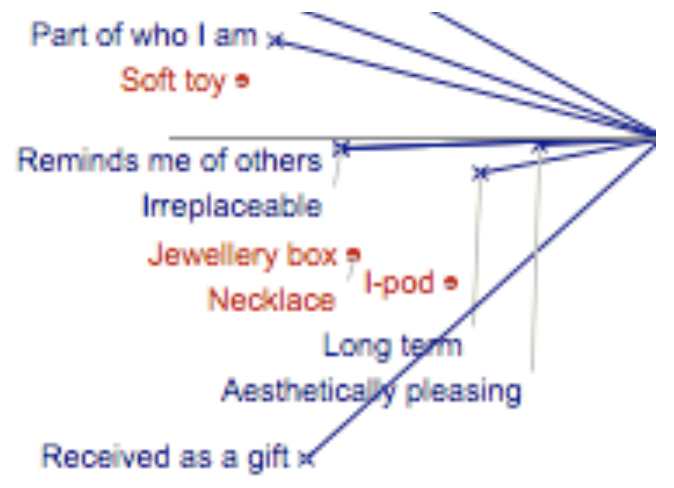

Figure 2: detail from the pringrid for participant A

Figure 3, similarly, is a detail from participant C. Notable here is the pairing of the teddy bear and the laptop at bottom left while a strong association between the constructs of "part of who I am", 
"personalised", "aesthetically pleasing" and "reminds me of others" can be seen, together with a pairing of "received as a gift" and "irreplaceable"

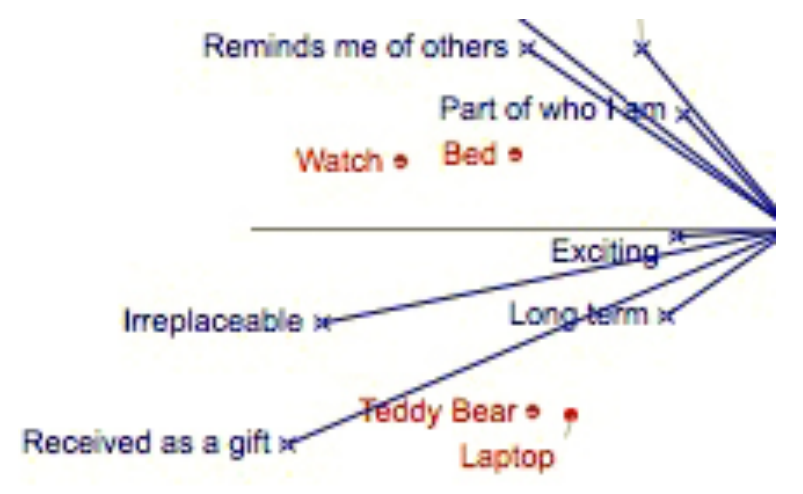

Figure 3: detail from the pringrid for participant $\mathrm{C}$

Other participants' interviews produced some noteworthy clusters or pairings of similarly construed artefacts, including the following: iPod, iPhone and photo album; mobile phone, old furniture and shoes; comic books and Xbox. From these first observations it is reasonable to say that people construe both kinds of artefact in similar ways. However, it is also evident from the data presented above and the remainder of the results that individuals' construction of the landscape of their domestic artefacts is idiosyncratic and diverse. Overall, what stands out is that some people are very much attached to some of their digital possessions. The association of constructs is also varied, both in degree and in the constructs associated. In the next section we consider the most common responses through the means of the aggregated data.

\subsection{Aggregated results}

Our aims in this study were not just to explore how different individuals might be attached to digital and non-digital possessions, but also to identify the common aspects of attachment. Following the practice of Fallman and Waterworth (2010) and other researchers, we therefore produced a composite grid. At this stage we were faced with over 50 different types of artefact each of which has been rated individually against the eight constructs. So as to reduce the data and produce a manageable composite grid which would afford interpretation, the most commonly chosen elements - those nominated by at least $20 \%$ of the interviewees - were identified. The resulting list is in table 2 below. The mode was then determined for each element. The mode was used rather than a mean or median value firstly because the bi-polar constructs comprise an interval scale and secondly since we were interested in the most common, rather than the average, experience. Grids were produced using Rep IV as before. As would be expected individual elements from the elicitation exercise varied very widely. We observed no clear patterns on the basis of age or gender. Common non-digital artefacts included jewellery, photographs through to items of furniture and clothing - please see table 2 which lists the most frequently elicited elements. For digital possessions, mobile phones, mp3 players, and laptops top the 
list. It is perhaps worth noting that in the full list of elements, the non-digital objects are more varied and include motor cars, a crochet hook and a hot-water bottle.

\section{Digital artefacts}

mobile phone

Laptop

desktop computer

mp3 player

(digital) camera

games console

television

\begin{tabular}{r|l} 
\% of participants & Non-digital artefact \\
citing it & \\
$76 \%$ & watch \& jewellery \\
$65 \%$ & photographs \\
$28 \%$ & clothing \& footwear \\
$39 \%$ & books \\
$38 \%$ & furniture \\
$34 \%$ & wallet/ purse/ handbag \\
$33 \%$ &
\end{tabular}

Table 2: the most frequently named elements
\% of participants citing it

$61 \%$

$44 \%$

$42 \%$

$25 \%$

$22 \%$

$21 \%$

It is interesting to observe in passing that most of these objects - with the obvious exception of recent innovations - figured among the items most frequently cited as "special" in Csikszentmihalyi and Halton-Roch's (1981) study.

Figure 4 below shows the Pringrid derived from the modal ratings of the elements listed in table 2 .

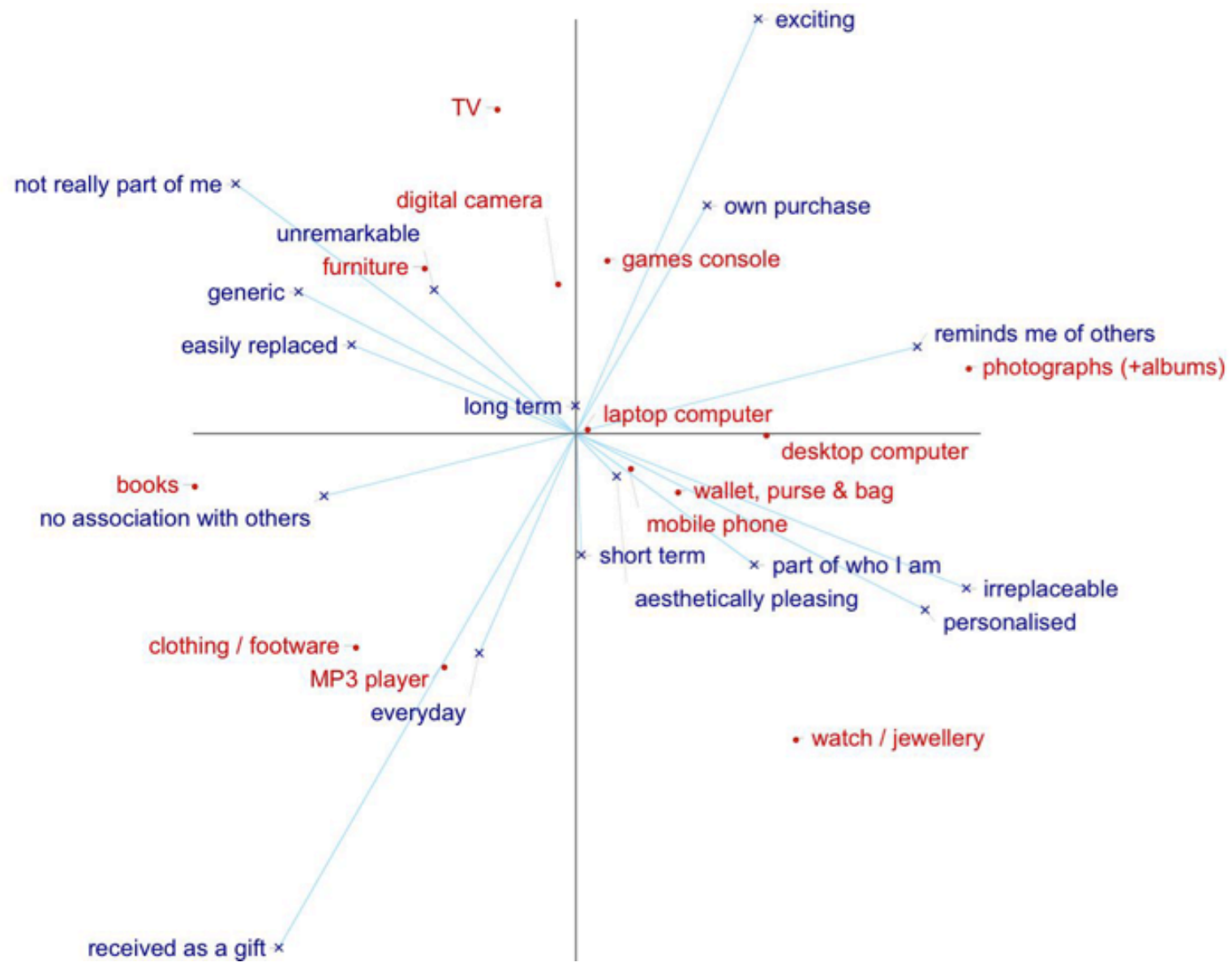

Figure 4: Pringrid from aggregated data 
Inspection of the aggregated Pringrid reveals an approximately even distribution of digital and nondigital objects across the four quadrants. In particular, the area of the grid where the attributes "reminds me of others", "irreplaceable", "personalised", "part of who I am" and "aesthetically pleasing" contains photographs, laptop and desktop computers, wallet purse and bag, mobile phone and watch/jewellery. At the other poles of these constructs, we find books, digital camera, furniture and TV.

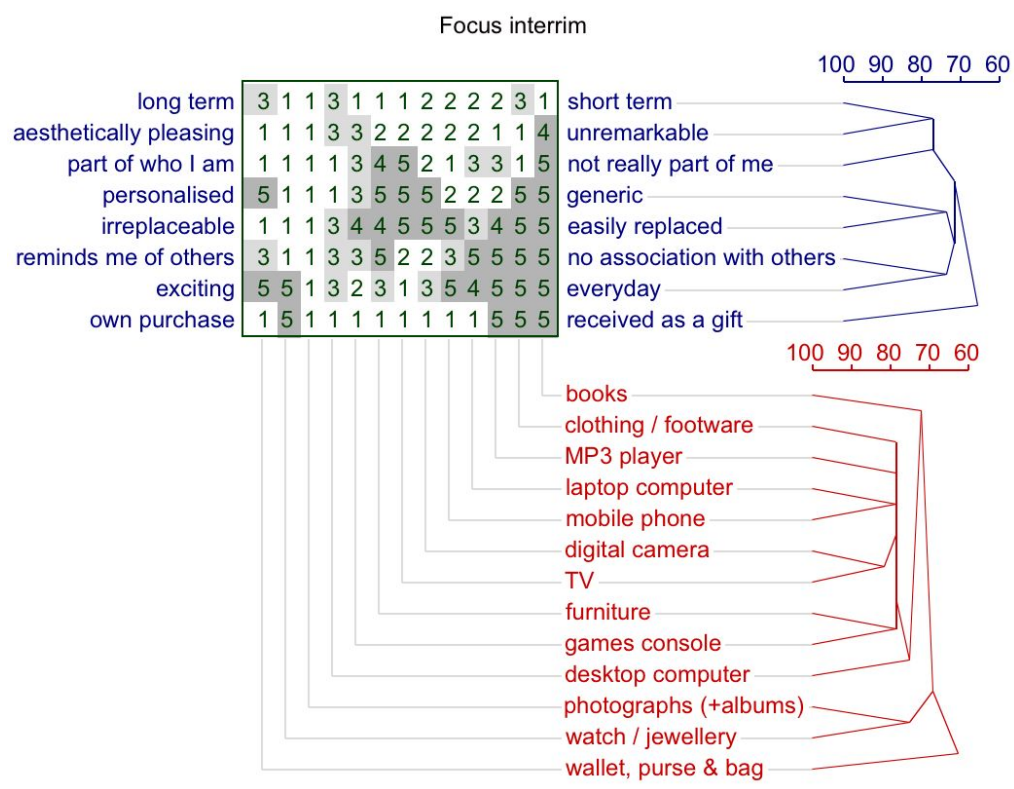

Figure 5: Focus graph from aggregated data

Figure 5 is the focus graph which presents these data as a dendrogram together with a measure of their association.

Consideration of the Focus graph indicates a close pairing between watch/jewellery and photographs, at around $75 \%$, and a much broader grouping of artefacts at around 80\%: games console, furniture, $\mathrm{TV}$, digital camera, mobile phone, laptop computer, $\mathrm{mp} 3$ player and clothing/footwear. There is no suugestion of a neat binary division between digital and non-digital possessions. Turning to the grouping of constructs, there is a strong association between "long term", "aesthetically pleasing" and "part of who I am" at just under $80 \%$ and a weaker but still interesting association between "personal", "irreplaceable", "reminds me of others" and "exciting".

\subsection{Findings from study I}

The clearest finding from this qualitative study is that people are attached to both digital and nondigital artefacts in ways which appear indistinguishable. This is striking as it is at odds with work reported by Odom and Pierce (2009) While we return to this work more fully in the concluding discussions of this work we were intrigued by Odom and Pierce's second observation that digital artefacts did not improve with age - there is, to coin a phrase, no desire for a digital patina. Our 
second study is, consequently, an examination of the role of the visual appearance of both types of artefact and attachment.

\subsection{Study II}

Until relatively recently there was comparatively little reported research concerning the aesthetics of interactive technologies. The reason for this may be related to reluctance by those in the field of computer science to compromise matters of substance and usefulness in favour of "mere appearance". While technical and analytical aspects are typical of this domain, the less tangible aspects such as "look and feel" are sometimes disregarded. However Norman (2004) claimed that aesthetic design can be even more important to the potential user than its usability, his now famous observation that "Attractive things are easier to use" (2002) being a sentiment echoing well established research in marketing, product design, and social / personality psychology.

Our follow-up research question is: "Are there differences between how we perceive the aesthetics of digital \& non-digital artefacts?"

\subsection{Method}

We followed the same method as study I. As before we conducted a pilot study to elicit 8 agreed constructs, beginning with the following instruction: "I would like you to think of 8 artefacts -4 digital and 4 non-digital - which you like, are fond of, care about because of its aesthetics, that is, you like it or use it because of how it looks or how it feels or its style and so on. Examples of digital artefacts include hardware and software. Non-digital artefacts are all other kinds of human-made objects (but not cats, dogs or sunsets)." We then used these elements and the triadic elicitation technique to identify the following constructs (table 3). As before, we evaluated these constructs using the rep grid process and slightly modified the wording in the light of this.

$\begin{aligned} \text { colourful } & \text { dull } \\ \text { rough } & \text { polished } \\ \text { brand new } & \text { used } \\ \text { unattractive } & \text { attractive } \\ \text { aspirational } & \text { everyday } \\ \text { ugly } & \text { beautiful } \\ \text { stylish } & \text { fussy } \\ \text { complex } & \text { simple }\end{aligned}$

Table 3: the most frequently named constructs

\subsubsection{Eliciting elements and applying the constructs}

The participants in this phase comprised sixty-four participants, a mixture of men and women in again in broadly equal proportions. Their ages ranged widely (between 20 and 63), but as before, most were in their twenties. All were unpaid volunteers. Each interviewee was asked to name four digital and four non-digital personal possessions and then to rate each of these elements against the supplied set 
of constructs, using a scale of 1 to 5 . The elicited data were analysed using the Rep IV analysis package.

\subsection{Individual and Aggregated Patterns of Attachment}

As with the first study these followed very similar patterns: we found, for example, that participant $\mathrm{C} 1$ views their Blackberry, shoes, old books and a particular CD as comparable artefacts in the notional space bounded by two groups of clustered concepts: (i) "beautiful", "attractive", stylish" and "aspirational" and (ii) "used" "rough" and "complex". While for participant A1 we observed pairing of the Macbook Pro and perfume bottle in the space populated by the associated constructs "stylish", and "attractive", coupled with "brand new".

Turning now to the aggregated data. This study revealed a total of 106 different types of artefact (each of which has been rated individually against the eight constructs). To reduce the data and produce a manageable composite grid we selected the most commonly chosen elements. In the first study we identified all artefacts cited by at least $20 \%$ of our participants, here only 6 of the 106 artefacts met this criterion - so we have reduced this threshold value to $10 \%$. As can be seen from table 4 , two digital artefacts dominated. Common non-digital artefacts included footwear and clothing while the digital inevitably included mobile phones and laptops. As in study I, the full list of non-digital artefacts is more varied and includes a katana, a stuffed alligator and a drum kit.

\section{Digital artefacts}

Mobile phone

Laptop

Television

Games console

\begin{tabular}{r|l} 
\% of participants & Non-digital artefact \\
citing it & \\
$81.8 \%$ & Footwear \\
$74.2 \%$ & Wallet/ purse/ handbag \\
$28.8 \%$ & Watch \\
$24.2 \%$ & Jacket / coat
\end{tabular}

Table 4: the most frequently named elements
$\%$ of participants citing it

$25.8 \%$

$24.2 \%$

$19.7 \%$

$13.6 \%$

Figure 6 below shows the PrinGrid for these aggregated data. From this figure (and the focus graph figure 10) we can seen that the aesthetics (and attachment) to TVs and games consoles is different from the remaining heterogeneous group of digital and non-digital artefacts. So what is it that unifies this group of used, dull (which we can understand as not gaudy as this stands opposite to colourful), complex and beautiful artefacts? Their everydayness is a possibility, though why TVs are excluded is difficult to justify. Instead a simple explanation is their physical (and perhaps existential) proximity to their owners and their owner's bodies specifically. All of these artefacts are either worn or are carried. 


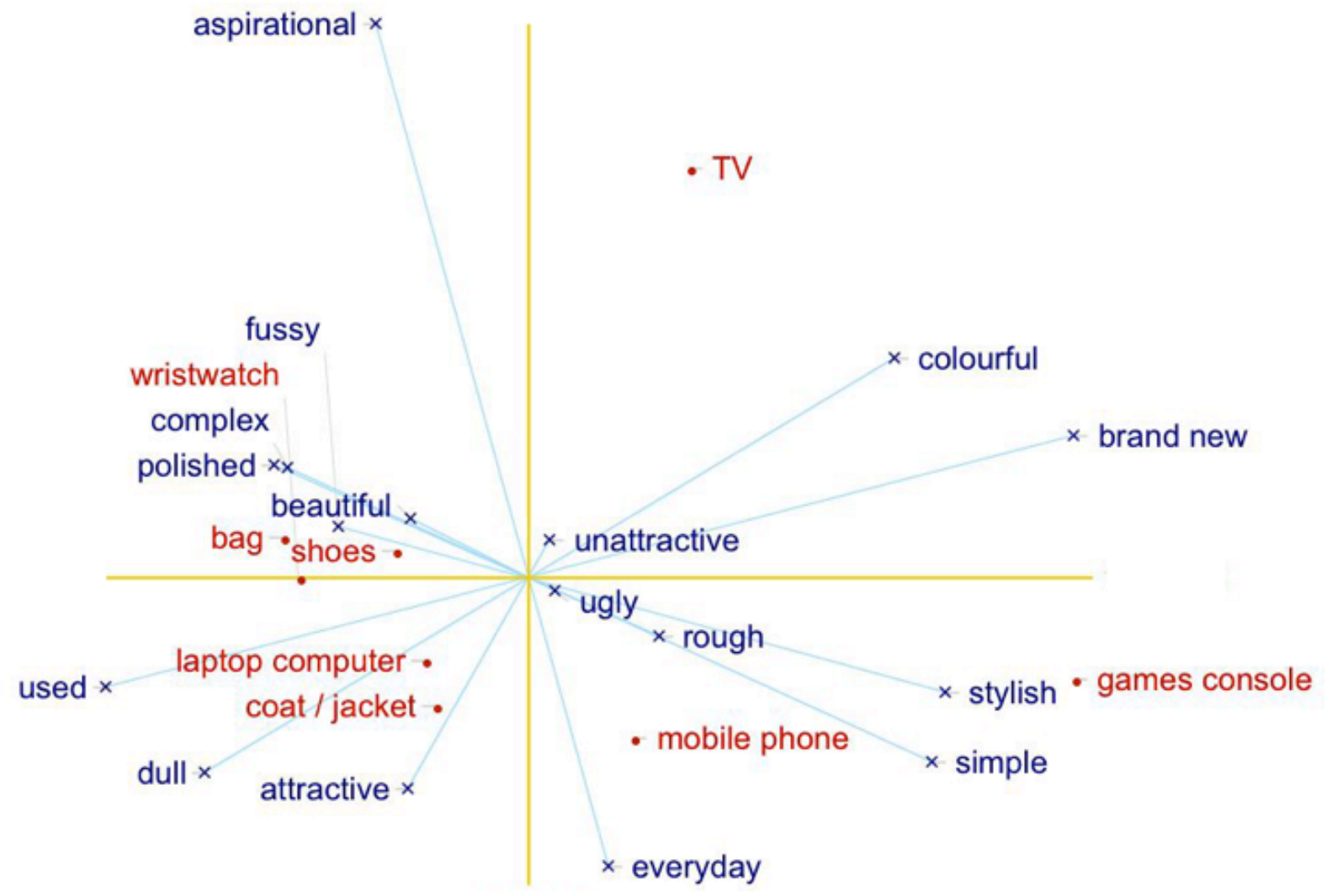

Figure 6: Pringrid from aggregated data

From figure 7, the Focus graph, we can see that laptop computer, bag, wristwatch, shoes, mobile phone and jacket show $80 \%$ association with TV and games console effectively being singletons.

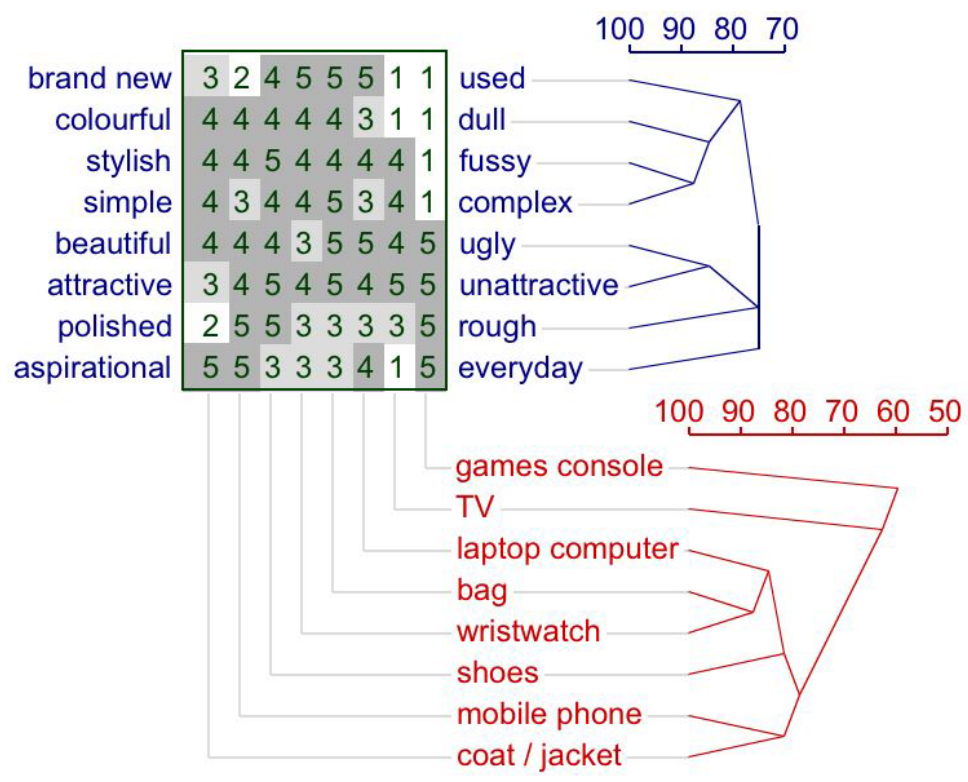

Figure 7: Focus graph from aggregated data 


\section{Discussion And Conclusions}

It was our unvoiced expectation that we (the authors) expected people to demonstrate greater attachment to non-digital rather than to digital artefacts. It seemed to us that there is something ephemeral about consumer electronics, as witnessed by the queues of people outside the Apple ${ }^{\mathrm{TM}}$ or Nintendo ${ }^{\mathrm{TM}}$ stores waiting to part with their money for the latest version of a technology which they probably already own. This stands in striking contrast to a favourite grandchild inheriting grandfather's pocket watch. The former is the product of smart design, smart advertising and a smart brand yet despite this smartness, the artefact will have been mass produced and quality controlled to ensure that it is identical to the artefact in the next box. It is a commodity (Borgmann, 1984).

Borgmann defines commodities as, "highly reduced entities and abstract in the sense that within the overall framework of technology they are free of local and historical ties. Thus they are sharply defined and easily measured."

Grandfather's pocket watch, in contrast, may not actually be a particularly good watch, but it will have acquired a literally and metaphorical patina. The watch will be old, worn and scuffed. The recipient will also know of or be told of its provenance, it may feature in stories about Grandfather and will have assumed the status of a family heirloom. It is a thing (ibid): things, "engage us in so many and subtle ways that no quantification can capture them.” (page 81).

In short, we expected to find evidence of attachment to grandfather's watch but not to his iPod. Specifically, these studies set out to answer the following questions:

1. What are the differences in emotional attachment between digital and non-digital artefacts?

2. Are there differences in the aesthetic attachment we have for digital \& non-digital artefacts?

We have already noted that we did not find qualitative differences in the patterns of attachment between digital and non-digital artefacts. People regard their desktop personal computer as "part of who I am" in the same way as they describe photographs or jewellery. Similarly a teddy bear (at least for one individual) is cherished in the same way their laptop. As for aesthetic attachment, while we noted some individual examples of preferring brand new over used digital artefacts, there was no overall (aggregated) evidence of patterns of differences between the two types of artefact. It may be that there are generational differences here, as identified by Csikszentmihalyi and Halton-Roch (1981), and this would repay investigation in a further study.

However, returning to Kleine and Baker's (2004) treatment of attachment who suggested that attachment is evidenced by appropriation, commodification and singularization. We now consider our data against these three dimensions. 
We found clear evidence of appropriation, in that people carried about with them small personal artefacts such as mobile phones, jewellery and photographs. This (physical) intimacy suggests that people are attached to things which they have made their own.

Turning now to de-commodification. We have found clear evidence for this too. People treat some digital artefacts in ways that suggests that they are things and not just commodities. This does not contradict Borgmann's sweeping sociological analysis but does suggest that there are exceptions to his observations at the individual level.

Finally, singularization - the exclusive use of an artefact - again there is evidence for this in both studies. There is a strong sense of ownership as expressed by the proximity of artefacts to which people are attached.

\subsection{Attachment, proximity and the presentation of the self}

While we are found evidence that both contradicts Borgmann at the personal level and challenges to the findings of the sustainable interaction design community, the most striking result for us is the role of proximity of artefact to person. The world for Heidegger was divided into that which is ready-tohand (proximal and available) and present-at-hand (distal and not available) and this distinction also finds form in these findings. We are emotionally and aesthetically attached to artefacts which are proximal and close at hand. Absence does not appear to make the heart grow fonder. However it is equally clear that is only one half of the equation as we only choose to have artefacts close to us if they are useful and meaningful expressions of who we are. Meschtscherjakov (2009) underlines this aspect of our attachment to digital artefacts writing, "mobile devices are also an expression of our personality and a symbol for our peer group membership they have become an extension of our self." Hassenzahl (2004) and Hassenzahl et al. (2011) also divide our experience with digital artefacts into the pragmatic (i.e. including utility, usefulness and usability) and the hedonic. The hedonic aspects of the artefact are either a source of stimulation, challenge or novelty and / or a means of selfpresentation of one's values. We suggest that this self-presentation is the outward expression of our emotional and aesthetic attachment to artefacts.

\subsection{Final words}

The study of user experience has become an important disciple in recent years, though for the main part, it has addressed our immediate or episodic experiences of digital artefacts. Research into long term user experience is yet to become fully realised and we would argue that the study of attachment has the potential to provide rich source of data. We conclude with a question, "can we be attached to something which is not proximal and available?" and what does this say for how designers wishing to create something to which we might become attached. 


\section{Acknowledgements}

Thanks to our anonymous reviewers for their thoughtful comments and to the students of the (MSc)

User Experience and the (undergraduate) Interactive Media Design programmes at Edinburgh Napier

University for their help with the data collection.

\section{References}

Akah, B. and Bardzell, S. (2010) Empowering Products: Personal Identity through the Act of Appropriation. Proc. CHI 2010: Work in Progress, pp. 4021-4026.

Bennett. J. (2001) The Enchantment Of Modern Life: Attachments, Crossings, and Ethics. Princeton: Princeton University Press

Blevis. E. (2007) Sustainable interaction design: invention \& disposal, renewal \& reuse. In Proc. CHI '08, New York: ACM Press, 503-512

Blom, J. and Monk, A. (2003) A theory of personalisation: why people personalise their PCs and mobile phones. Human Computer Interaction, 18, pp. 193-228.

Borgmann, A. (1984) Technology and the Character of Contemporary Life. Chicago, The University of Chicago Press.

Bowlby, J. (1969) Attachment and Loss. Volume 1: Attachment. Harmondsworth: Penguin.

Brinkman, W.-P. and Love, S. (2006) Developing an instrument to assess the impact of attitude and social norms on user selection of an interface design: a repertory grid approach, Proceedings of ECCE-13, 129-136.

Csikszentmihalyi, M. and Halton-Roch, E. (1981) The meaning of things, Cambridge: Cambridge University Press

Davis, M. (2003) Theoretical Foundations For Experiential Systems Design. Proc. ETP'03:

Proceedings of the 2003 ACM SIGMM workshop on Experiential Telepresence, Berkeley, California, 45-52.

Dillon, A. and McKnight, C. (1990) Towards a classification of text types: a repertory grid approach. International Journal of Man-Machine Studies, 33, 623-636.

DiSalvo, C., Brynjarsdóttir, H. and Sengers, P. (2010) Mapping the Landscape of Sustainable HCI, Proceedings of CHI' 10, New York: ACM Press, 1975-1984

Edwards, H.M., McDonald, S. and Young, S.M. (2009) The repertory grid technique: Its place in empirical software engineering research. Information and Software Technology, 51, 785-798

Fallman, D. and Waterworth, J. (2010) Capturing user experiences of mobile information technology with the repertory grid technique. Human Technology, 6(2), 250-268

Fransella, F. and Bannister, D. (1977) A Manual For Repertory Grid Technique. Academic Press. Fransella, F., Bell, and Bannister, D. (2004) A Manual for Repertory Grid Technique, Chichester: John Wiley and Sons.

Hassard, J. (1987) FOCUS: as a phenomenological technique for job analysis: its use in multiple paradigm research (MPR). International Journal of Man-Machine Studies, 27, 251-280.

Hassenzahl, M. (2004) The Interplay of Beauty, Goodness, and Usability in Interactive Products. Human-Computer Interaction, 19(4), 319-349

Hassenzahl, M., Platz, A., Burmester, M. and Lehner, K. (2011) Hedonic and Ergonomic Quality Aspects Determine a Software's Appeal. CHI Letters, 2(1), 201-208

Kagan, J., Kearsley, R. and Zelago, P.R. (1978) Infancy - Its place in human development. Cambridge MA: Harvard University Press.

Kelly, G. A. (1955) The Psychology of Personal Constructs. New York: Norton.

Kelly, G. A. (1969) The role of classification in personality theory. In B Maher (Ed.) Clinical

Psychology and Personality: the selected papers of George Kelly. Wiley: New York. 
Kleine, S.S. and Baker, S.M. (2004) An Integrative Review of Material Possession Attachment. Academy of Marketing Science Review. 2004(1), available from

https://www.uwyo.edu/mgtmkt/faculty-staff/facultypages/docs/baker/material\%20possession\%20attachment.pdf [last retrieved 29 ${ }^{\text {th }}$ February, 2012] Lorenz, K. (1935) The companion in the bird's world. Auk, 54, 245-273.

McCarthy, J., Wright, P., Wallace, J. and Dearden, A.M. (2005) The experience of enchantment in human-computer interaction. Personal and Ubiquitous Computing. 10(6), 369-378

McCarthy, J.C. and O'Connor, B. (1998) The Context of Information Use in a Hospital as Simultaneous Similarity-Difference Relations. Cognition, Technology \& Work, 1(1), 25-36.

McWhinnie, S., O'Neill, S.J. and Valentine, L. (2009) Random thinking, ordered doing: understanding group creative practice through repertory grid technique. Proceedings of ACM conference on Creativity and Cognition. New York: ACM Press, 137-146

Meschtscherjakov, A. (2009) Mobile Attachment - Emotional Attachment Towards Mobile Devices and Services. Proceedings of the 11th International Conference on Human-Computer Interaction with Mobile Devices and Services. ACM New York, NY, USA

Nelson, H.G. and Stolterman, E. (2003) Design Way: Intentional Change in an Unpredictable World. Englewood Cliffs: Educational Technology Publications

Norman, D. A. (2002) Emotion and design: Attractive things work better. Interactions Magazine, ix(4), 36-42.

Odom, W. and Pierce, J. (2009) Improving with Age: Designing Enduring Interactive Products. In Extended Abstracts of CHI '09. New York: ACM Press

Odom, W., Pierce, J., Stolterman, E. and Blevis, E. (2009) Understanding why we preserve some things and discard others in the context of interaction design. Proceedings of CHI '09, New York: ACM Press, 1053-1062

Prümper, J., Zapf, D., Brodbeck, F.C., and Frese, M. (2002) Some surprising differences between novice and expert errors in computerized office work. Behaviour \& self report. Psychological Bulletin. 128(6), 934-960.

Schultz, S. E., Kleine, R. E. and Kernan, J. B. (1989) “'These Are a Few of My Favorite Things': Toward an Explication of Attachment as a Consumer Behavior Construct". In (Ed.) T. K. Srull Advances in Consumer Research, 16, Provo, UT: Association for Consumer Research, 359-66 Shaw, M.L.G. and Gaines, B. (1987) KITTEN: Knowledge elicitation and transfer tool for experts and novices. International Journal of Man-Machine Studies, 27, 251-280.

Shaw, M.L.G. and Gaines, B. (1992) Kelly's "Geometry of Psychological Space" and its Significance for Cognitive Modelling. The New Psychologist, 23-31

Star, S. L. (1989) The structure of ill-structured solutions: Boundary objects and heterogeneous distributed problem solving. In M. Huhns and L. Gasser (Eds) Readings in Distributed Artificial Intelligence. Menlo Park Ca: Morgan Kaufman

Tan, F. B., \& Hunter, M. G. (2002). The repertory grid technique: A method for the study of cognition in information systems. MIS Quarterly, 26, 39-57.

Turner, P. (2000) Requirements Are In The Eyes Of The Beholders, People and Computers XV - The Proceedings of HCI Conference, 33-44.

Turner, P. (2008) Being-with: A Study of Familiarity. Interacting with Computers. 20, 447-454.

Turner, P. and Sobolewska, E. (2009) Familiarity with Mobile Phones. Proc. European Conference on Cognitive Ergonomics, 80-89.

Verbeek, P-P. (2005) What Things Do: Philosophical Reflections on Technology, Agency and Design. Pennsylvania: The Pennsylvania State Press

Wells, M. (2000) Office clutter of meaningful personal displays: the role of office personalization in employee and organizational well-being. Journal of Environmental Psychology, 20, 239-255. 